\title{
One-Pot Alkene Hydroboration/Palladium-Catalyzed Migratory Suzuki-Miyaura Cross-Coupling
}

\author{
Yann Baumgartner and Olivier Baudoin*
}

\begin{abstract}
Chain-walking is a powerful approach toward the functionalization of $\mathrm{C}-\mathrm{H}$ bonds remote to a functional group. Whereas various $\mathrm{Pd}-$ catalyzed migratory cross-couplings have been developed in the past years, the design of an efficient migratory version of the popular Suzuki-Miyaura cross-coupling has remained elusive. The current article reports a one-pot procedure consisting of alkene hydroboration and migratory Suzuki-Miyaura coupling of the resulting alkylboronic acid intermediate. A high

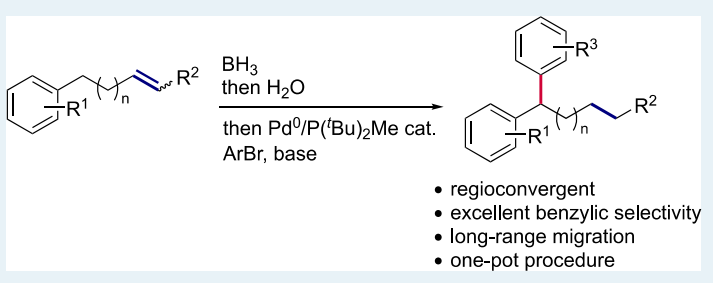
regioselectivity for the benzylic position of the initial alkene was achieved by using $\mathrm{P}(t-\mathrm{Bu})_{2} \mathrm{Me}$ as the ligand and an ortho-substituted aryl electrophile. Regioconvergence from alkene positional and geometrical isomers and long-range migration were demonstrated. Mechanistic investigations indicated that the migration occurs through a partially reversible, nondissociative mechanism.
\end{abstract}

KEYWORDS: $C-C$ coupling, chain-walking, palladium, regioconvergence, remote functionalization

\section{INTRODUCTION}

Transition-metal-catalyzed cross-coupling reactions have been extensively developed and are now an essential tool for advanced organic synthesis. ${ }^{1}$ Yet, these methodologies rely on the direct transformation at prefunctionalized and/or acidic positions of the reaction partners. In this context, the replacement of an unactivated $\mathrm{C}-\mathrm{H}$ bond with a functional group, termed $\mathrm{C}-\mathrm{H}$ bond functionalization, is a desirable yet challenging step-economical approach to functionalized organic intermediates and has been under intense investigations in the last two decades. ${ }^{2}$ While $\mathrm{C}\left(\mathrm{sp}^{2}\right)-\mathrm{H}$ functionalization has grown into a mature tool, the extension to alkyl $\mathrm{C}-\mathrm{H}$ bonds has proven to be more difficult owing to the lesser reactivity of these bonds toward organometallic bond cleavage. ${ }^{3}$ These issues have mainly been addressed by using "innate" reactivity (based on electronic, steric, or stereoelectronic factors), the use of a leaving or directing group, and ligand design.

More recently, a different approach enabling bond construction at a remote unfunctionalized $\mathrm{C}\left(\mathrm{sp}^{3}\right)-\mathrm{H}$ site has received increasing attention. This process, termed "chainwalking", operates via dynamic displacement of a transitionmetal catalyst along an alkyl chain, often associated with the translocation of a double bond, to a terminal position, presumably due to steric effects or due to a resonancestabilized position such as the one adjacent to an aromatic group or heteroatom. ${ }^{4}$ Significant progress in remote $\mathrm{C}-\mathrm{H}$ functionalization through chain-walking has already been achieved with different transition metals such as $\mathrm{Zr}^{5}{ }^{5} \mathrm{Co},{ }^{6}$ $\mathrm{Ni}^{7} \mathrm{Ru},{ }^{8}$ or $\mathrm{Pd} .^{9-11}$ Previous reports from our research group on palladium $(0)$-catalyzed migratory cross-couplings relied on ligand-controlled chain-walk with enolates as nucleophiles ${ }^{10}$ or organozinc compounds obtained by directed lithiation and $\mathrm{Li}-$ $\mathrm{Zn}$ transmetalation or under Barbier conditions (Figure 1a). ${ }^{11,12}$ To further expand and demonstrate the power of the remote $\mathrm{C}-\mathrm{H}$ functionalization toolbox, we designed a benzylic-selective migratory Suzuki-Miyaura cross-coupling reaction (Figure 1b). ${ }^{13}$ Undesired migration products were previously observed in B-alkyl Suzuki-Miyaura cross-couplings, ${ }^{14}$ but these migratory cross-couplings have not been synthetically exploited.

Ideally, the organoboron reagent would be synthesized upon simple hydroboration of an alkene with borane and subsequent quenching with water, generating an inconsequential regioisomeric mixture of alkylboronic acids owing to the low regioselectivity of the hydroboration step. The crude reaction mixture would then be engaged in a one-pot manner into the palladium-catalyzed migratory cross-coupling, hence avoiding the occasionally difficult purification and isolation of alkylborane intermediates. The different boronic regioisomers would be convergently transformed to a single cross-coupling product with an aryl halide coupling partner, ${ }^{11 \mathrm{c}}$ generating $1,1-$ diarylalkanes, which are structural motifs present in natural or synthetic bioactive molecules (Figure 1c). ${ }^{15}$ The selectivity would be achieved by careful selection of the ancillary ligand 
a)

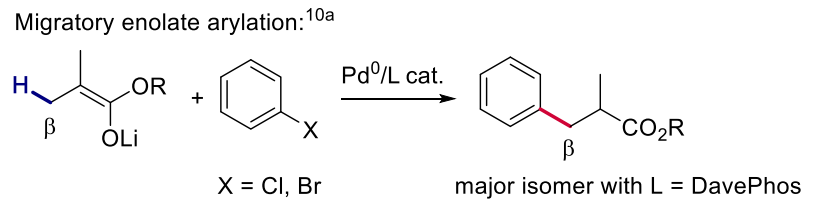

Migratory Barbier-Negishi coupling: ${ }^{11 \mathrm{c}}$

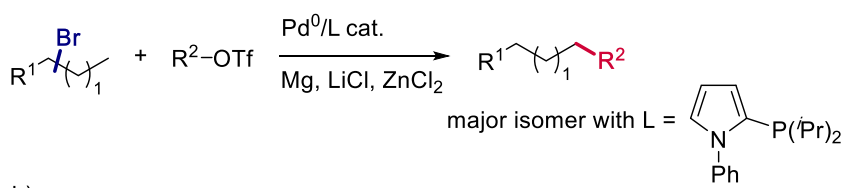

b)

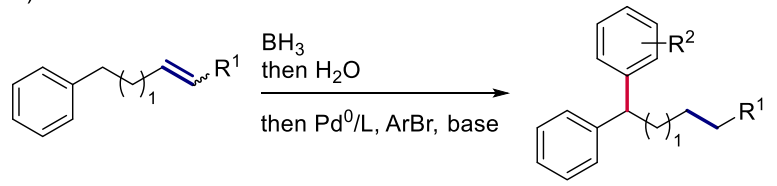

c)

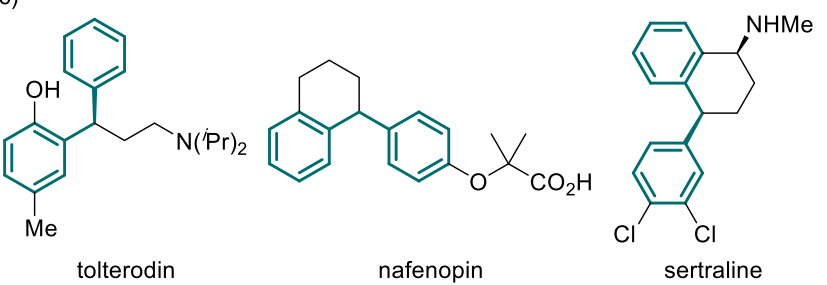

Figure 1. (a) Initial report and terminal-selective functionalization of alkyl chains by our group. (b) This work on the one-pot hydroboration/benzylic-selective Suzuki-Miyaura coupling. (c) Selected examples of biologically active 1,1-diarylalkanes. DavePhos = 2-dicyclohexylphosphino-2'-(N,N-dimethylamino $)$ biphenyl.

on the palladium as well as steric and electronic properties of the electrophilic coupling partner, directly impacting the properties of the organopalladium intermediates. ${ }^{10,11}$ Accordingly, it should be possible to enhance the kinetics of the $\beta$ hydride elimination against the direct reductive elimination until palladium reaches a thermodynamically favored benzylic position, from which reductive elimination becomes more favorable, hence furnishing the desired benzylic functionalized products. Besides recent reports on nickel-catalyzed benzylicselective migratory arylations employing arylboronic acids ${ }^{71, \mathrm{~m}}$ and on a migratory allylic arylation reaction, ${ }^{9 m}$ this work represents to the best of our knowledge the first example of a palladium-catalyzed benzylic-selective migratory SuzukiMiyaura cross-coupling of B-alkyl boronic acids and aryl halides.

\section{RESULTS AND DISCUSSION}

We initiated our studies with the modification of a one-pot procedure for the generation and Suzuki-Miyaura crosscoupling of linear trialkylboranes with aryl halides from $\mathrm{Li}$, Zhong, and co-workers. ${ }^{14 \mathrm{~b}}$ Interestingly, the authors observed some migration along the alkyl chain when the reaction was performed from tri $\left(\sec\right.$-butyl)borane with $\left({ }^{n} \mathrm{Bu}\right)_{2}$ PAd (cataCXium A) as the ligand, resulting in a 4:1 mixture of direct and migratory coupling products (Scheme 1a). We first tested our hypothesis with different alkene substrates (Scheme 1b). With alkene 1a, the migration was favored using $\mathrm{P}\left({ }^{t} \mathrm{Bu}\right)_{2} \mathrm{Me}$ as the ligand (vide infra), but the competition for the site of reductive elimination between the benzylic and terminal position was significant. Increasing the steric bulk of the terminal position
Scheme 1. Initial Results; (a) Observation of a Migratory Coupling with Tri(sec-butyl)borane; (b) Preliminary Investigations on Regioselectivity ${ }^{a}$
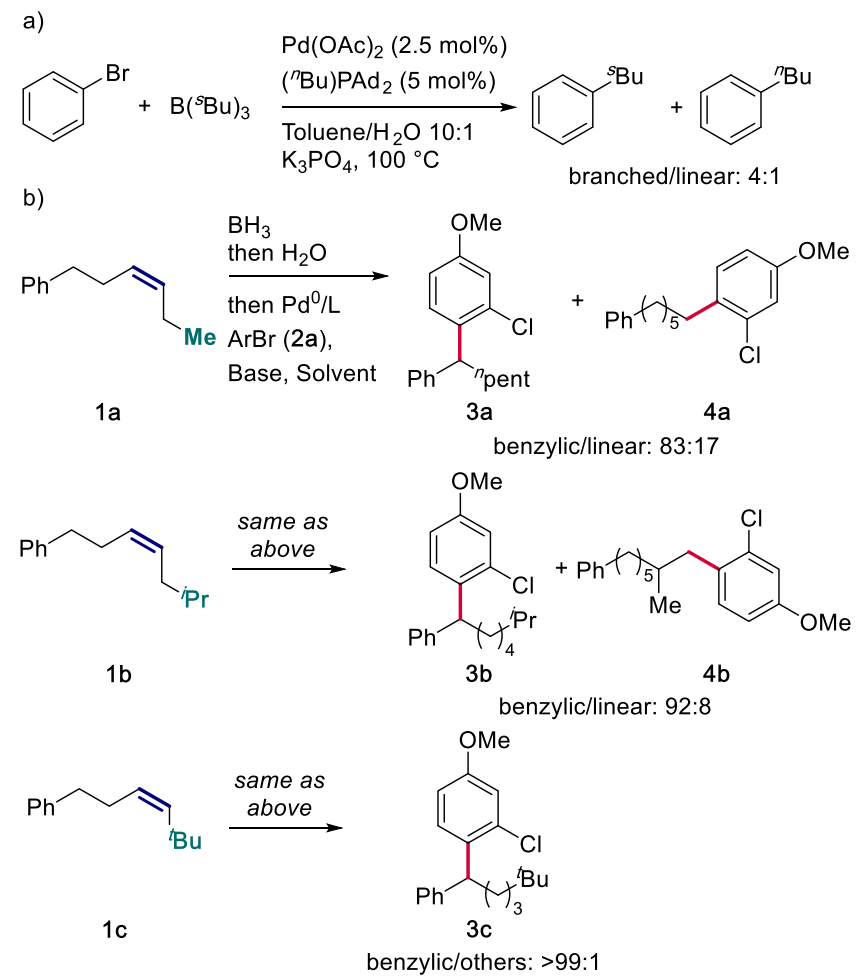

${ }^{a}$ Reaction conditions: alkene (1.0 equiv), $\mathrm{BH}_{3} \cdot \mathrm{DMS}$ (0.4 equiv), toluene, $50{ }^{\circ} \mathrm{C}, 1 \mathrm{~h}$, then quench with $\mathrm{H}_{2} \mathrm{O}$, then add $\operatorname{ArBr}(1.1$ equiv), $\mathrm{Pd}_{2} \mathrm{dba}_{3}(2.5 \mathrm{~mol} \%), \mathrm{P}\left({ }^{t} \mathrm{Bu}_{2}\right) \mathrm{Me}(10 \mathrm{~mol} \%), \mathrm{Cs}_{2} \mathrm{CO}_{3}(2.0$ equiv), toluene $/ \mathrm{H}_{2} \mathrm{O}[0.42 \mathrm{M}], 100{ }^{\circ} \mathrm{C}, 18 \mathrm{~h}$. Regioisomeric ratios were determined by GCMS analysis of the crude reaction mixture.

with an isopropyl group (alkene $\mathbf{1 b}$ ) gave, as expected, a better selectivity in favor of the benzylic position. However, to reach excellent levels of regioselectivity, a blocking group such as tertbutyl was required to completely exclude the migration of the catalyst to the terminal position (alkene 1c). Indeed, and to our delight, we observed exclusive benzylic selectivity when using $\mathrm{P}\left({ }^{t} \mathrm{Bu}\right)_{2} \mathrm{Me}$ as the ligand and an $o$-chloro-substituted aryl bromide, the two key factors which favor the migration of the palladium complex along the alkyl chain. ${ }^{10-12}$

With these preliminary results in hand, we moved on with the optimization of the reaction conditions for the benzylicselective migratory cross-coupling of $(Z)$-(5,5-dimethylhex-3en-1-yl)benzene (1c) and bromobenzene (2b) (Table 1). As the selectivity of the hydroboration step does not affect the general outcome of the reaction, we retained the borane dimethyl sulfide complex as a cheap and easy-to-handle hydroboration reagent. ${ }^{11} \mathrm{~B}$ NMR of the hydroboration crude mixture indicated quantitative conversion to the secondary alkylboronic acid (Figure S3). When comparing different ligands, we only obtained a 7:93 ratio of the benzylic product/ other regioisomers using cataCXium $A$ and a 78:22 ratio with RuPhos. ${ }^{14} \mathrm{PCy}_{3}$, which favored the migratory product in enolate arylations, ${ }^{10 a}$ furnished a 49:51 ratio, and cataCXium PiPr, which provided optimal selectivities in migratory Negishi couplings, ${ }^{11}$ gave only a 21:79 ratio, thus highlighting the differences between the previous and current migratory crosscoupling reactions (entry 1-4). Gratifyingly, we obtained an excellent yield and regioselectivity when using the small and 
Table 1. Optimization of the Reaction Conditions

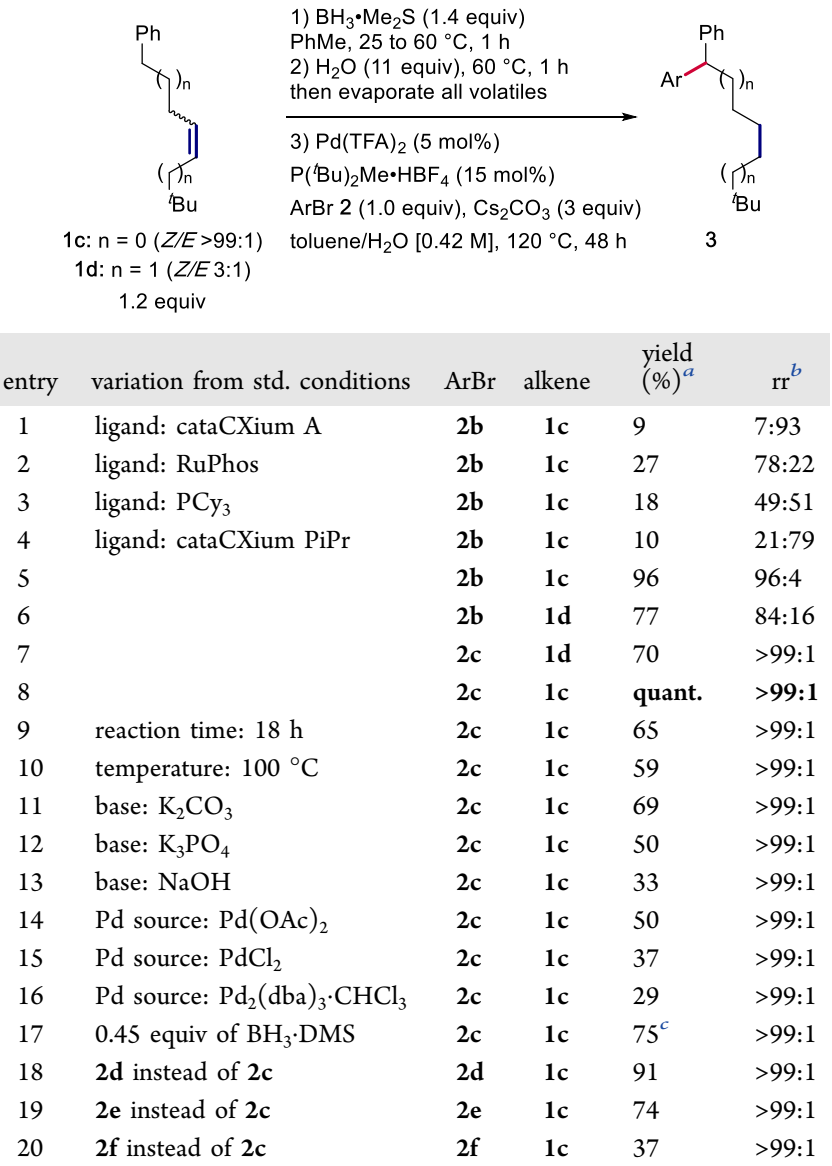

${ }^{a}$ Yield determined by ${ }^{1} \mathrm{H}$ NMR using $\mathrm{CH}_{2} \mathrm{Br}_{2}$ as the internal standard. ${ }^{b}$ Regioisomeric ratio of benzylic/sum of other regioisomers determined by GCMS analysis. 'Yield of the isolated product.

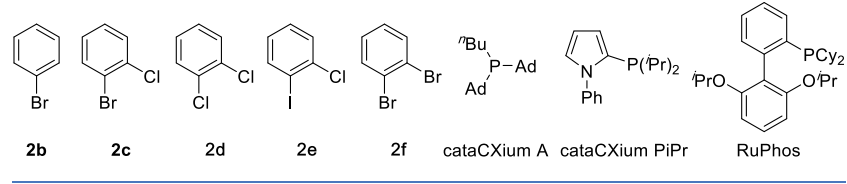

electron-rich ligand $\mathrm{P}\left({ }^{t} \mathrm{Bu}\right)_{2} \mathrm{Me}$ (entry 5). ${ }^{16}$ Indeed, such ligands are known to facilitate $\beta-\mathrm{H}$ elimination and $\mathrm{Pd}$ migration over direct reductive elimination. ${ }^{10,11,17}$ However, the regioselectivity decreased significantly when the chain was elongated on both sides of the alkene by just one methylene unit (entry 6). Presumably, the steric bulk of the tert-butyl group on the substrate with a shorter chain (1c) is sufficient to favor the chain-walk, but this effect weakens with a longer chain (1d). The loss in regioselectivity could be recovered when 1-bromo-2-chlorobenzene (2c) was used as electrophile to furnish the benzylic product in high yield and perfect regioselectivity (entries $7-8$ ), as it has been demonstrated that ortho-substituents disfavor the direct reductive elimination and favor the migration pathway. ${ }^{10 a, 11 \mathrm{c}}$ The rather high temperature and long reaction time were required for good results (entries 9-10), and other bases which are typically used in Suzuki-Miyaura couplings led to significant drops in yield without affecting the selectivity of the chain-walk (entries 1113). Different Pd sources were also screened (entries 14-16), and intriguingly, when using $\mathrm{Pd}_{2}(\mathrm{dba})_{3} \cdot \mathrm{CHCl}_{3}$ the yields were significantly lower (entry 16). Furthermore, diminishing the amount of borane, and favoring the formation of the tri $(\mathrm{sec}-$ alkyl)borane intermediate, led to a slight decrease in yield, presumably because of the lower transmetalation rate of the latter compared to the corresponding alkylboronic acid (entry 17).$^{18}$ Nevertheless, it is noteworthy that the developed system is able to react with the three secondary alkyl moieties of this trialkylborane, which is to date, unmet in a general protocol. ${ }^{14 \mathrm{~b}, 19}$ Finally, other $o$-dihalobenzenes were tested (entries 18-20). Although $o$-dichlorobenzene $\mathbf{2 d}$ also furnished good results (entry 18), they were all less efficient than $o$-chlorobromobenzene $2 \mathrm{c}$ (entry 8 ).

Using the optimized conditions described in Table 1, entry 8 , we then investigated the generality of the benzylic-selective migratory Suzuki-Miyaura cross-coupling reaction (Figure 2). We first evaluated the scope of the alkenes with 1-bromo-2chlorobenzene (2c) as the electrophile (Figure 2a). A range of alkenes, bearing electron-rich or electron-withdrawing substituents in ortho- (3d, 3e), meta- (3f, $\mathbf{3 g}$ ), and para-position (3h, 3i) of the initial aryl moiety and a disubstituted 1,2methylenedioxybenzene $(3 \mathbf{j})$ were all well-tolerated. Importantly, pure $(Z)$ - (3c, 3d, 3o, 3p), (E)-alkenes (3n, 3q-3ae), as well as $E / Z$ mixtures $(\mathbf{3 e}-\mathbf{3 m})$ underwent hydroboration and migratory Suzuki-Miyaura cross-coupling without noticeable impact on the efficiency and selectivity. Remarkably, excellent results were obtained with a longer-chain alkene as the starting material, yielding product $3 \mathbf{k}$ in high yield and excellent regioselectivity with a migratory distance of 10 positions with respect to the initial alkene. Besides a tert-butyl moiety to block the terminal position, the reaction was also found to be compatible with a tert-butyl ether (3n, 3q-3ae) or a cyclohexyl group (3m), with the former enabling further functional group transformation at this end of the alkyl chain. The practicability of this reaction was further demonstrated by conducting the reaction on a 10 -fold larger scale $(5.0 \mathrm{mmol})$ and without the use of a glove box for the synthesis of the model product 3c. The latter was obtained in $91 \%$ yield and excellent selectivity, with the slightly lower yield mainly arising from a difficult purification. In addition, as discussed previously, very good regioselectivites were obtained without an ortho-substituent on the aryl bromide, provided that the terminal position was blocked and the migration distance was short (3o, 3p).

We then investigated the scope of the electrophiles with $(E)$ (6-(tert-butoxy)hex-3-en-1-yl)benzene (1e) as the alkene (Figure 2b). We first evaluated 1-bromo-2-chlorobenzene containing additional substituents. Electrophiles with both electron-rich and electron-withdrawing substituents in para$(3 q-3 t)$ and both meta-positions $(3 \mathbf{u}-3 \mathbf{x})$ with respect to the formed bond reacted in moderate to good yields and high regioselectivities. Disubstitution and a heteroaromatic electrophile were also tolerated as shown with a dioxolane (3ab), an indole (3ac), and a pyridine (3ad), although the reaction was less selective with the latter. Moreover, the reaction was more sluggish with a 2,6-disubstituted aryl bromide bearing an electron-rich substituent (3ae). Importantly, the chloride ortho-substituent could be replaced with a methyl (3y), a methoxy (3z), or a trifluoromethyl group (3aa) to obtain ortho-substituted products in good yields and excellent regioselectivities, hence showing that the ortho substituent mainly exerts a steric effect on the selectivity (vide infra).

The obtained products were then further transformed to demonstrate the versatility of products accessible through this reaction (Scheme 2). The chloride, which was used to amplify the selectivity, could efficiently be removed by Pd-catalyzed 


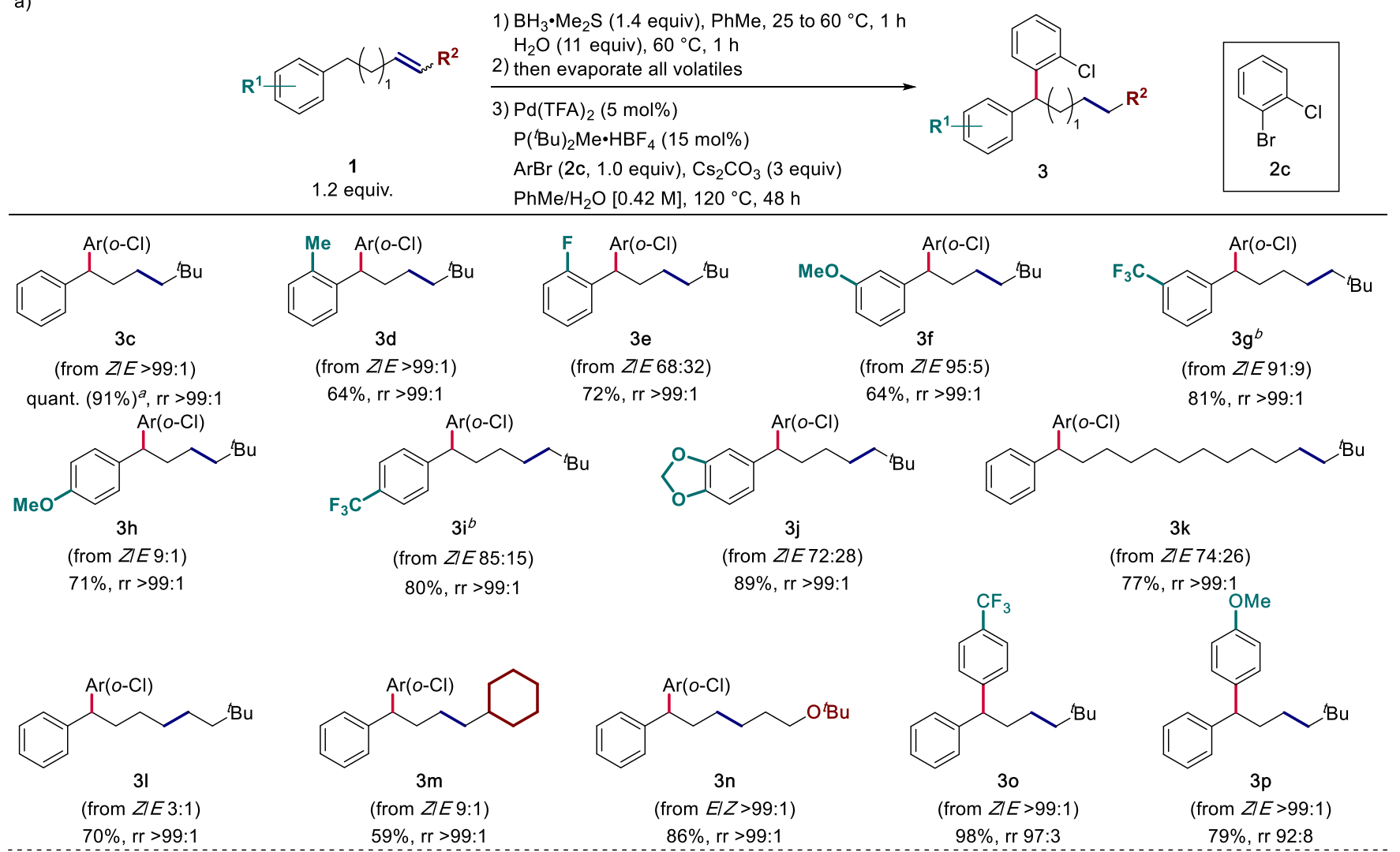

b)
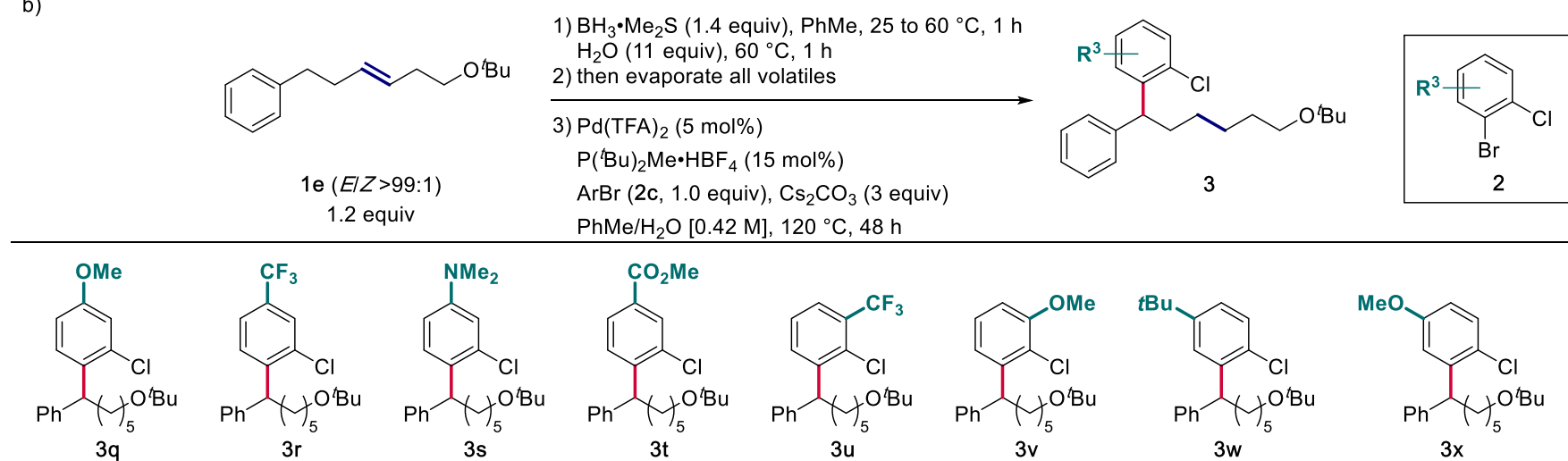
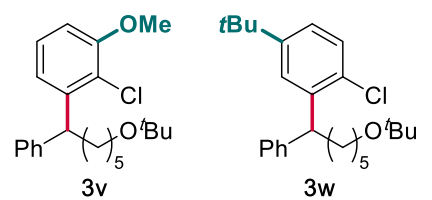

$3 w$

$57 \%$, rr $>99: 1$<smiles>CCOC(C)(C)C(c1ccccc1)C(c1ccccc1)c1ccc2ccn(C)c2c1</smiles>

$53 \%, r r>99: 1$

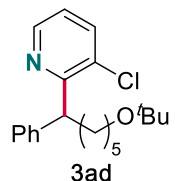

$39 \%$, rr $92: 8$

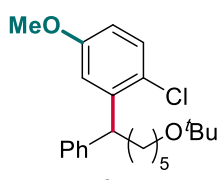

$3 x$

$64 \%, r r>99: 1$

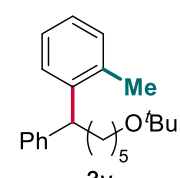

$80 \%$, rr $>99: 1$

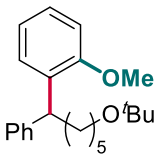

$57 \%$, rr $>99: 1$

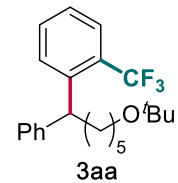

$65 \%, \mathrm{rr}>99: 1$

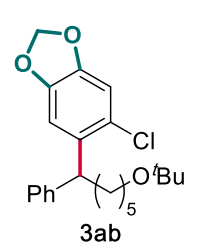

$61 \%$, rr $>99: 1$

Figure 2. Scope of the migratory Suzuki-Miyaura cross-coupling. The geometry of the initial alkene is indicated in parenthesis, and the initial position of the alkene is highlighted in dark blue. Scale of the reactions: $0.50 \mathrm{mmol}$ unless otherwise noted. Yields refer to the isolated product. Regioisomeric ratios (rr) of benzylic/sum of other regioisomers were determined by gas chromatography-mass spectrometry (GCMS) analysis of

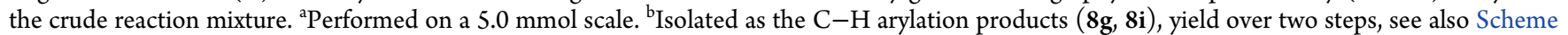
2. (a) Scope of alkenes. (b) Scope of electrophiles.

dehalogenation to give compound $\mathbf{5},{ }^{20}$ thus serving as a removable directing group (Scheme $2 \mathrm{a}$ ). In addition, the tertbutyl ether on the end of the alkyl chain (compound 3n) was cleaved under classic conditions to give the primary alcohol 6 quantitatively. The aryl chloride could also be employed to perform further chemistry as shown by the coupling with $p$ anisylboronic acid under classical Suzuki-Miyaura conditions (product $7,92 \%$ yield) or by the intramolecular $\mathrm{C}\left(\mathrm{sp}^{2}\right)-\mathrm{H}$ arylation to obtain alkylfluorene $\mathbf{8 c}{ }^{21}$ Two other fluorenes $(\mathbf{8 g}$, 
Scheme 2. Removal of the $o-\mathrm{Cl}$ and ${ }^{t} \mathrm{Bu}$ Groups,

Postfunctionalization and Example of Regioconvergent Coupling; (a) Removal of Directing and Protecting Group; (b) Postfunctionalization; (c) Regioisomeric Mixture of Alkenes $^{a}$

a)<smiles>Clc1ccccc1C(CCCBr)PC(Br)(Br)Br</smiles>
$\mathrm{NaO}$ Bu (1.05 equiv) [(IPr)Pd(allyl)Cl] (0.5 mol\%)

PrOH, MW

$120^{\circ} \mathrm{C}, 4 \mathrm{~min}$

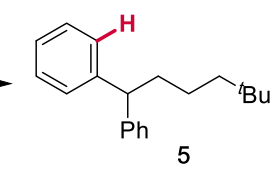

quant.<smiles>CCCCOCCCCC(c1ccccc1)c1ccccc1Cl</smiles>

$3 n$<smiles>Clc1ccccc1C(CCCBr)c1ccccc1</smiles>

$3 c$

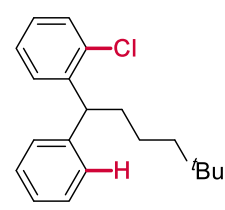

$3 c$

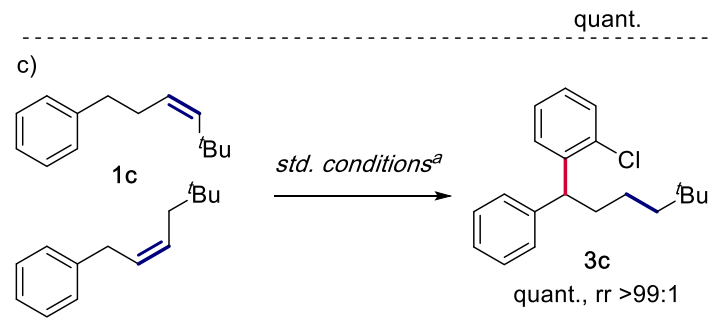

$1 f$

0.6 equiv of each

${ }^{a}$ Standard reaction conditions: 1 c ( 0.6 equiv), $\mathbf{1 f}$ ( 0.6 equiv), $\mathrm{BH}_{3}$. DMS (1.4 equiv), toluene, $25 \rightarrow 60{ }^{\circ} \mathrm{C}, 1 \mathrm{~h}$, then quench with $\mathrm{H}_{2} \mathrm{O}$ (11 equiv), $60^{\circ} \mathrm{C}, 1 \mathrm{~h}$, then add $o$-chlorobromobenzene (1.0 equiv), $\mathrm{Pd}(\mathrm{TFA})_{2}$ (5 mol \%), $\mathrm{P}\left({ }^{t} \mathrm{Bu}_{2}\right) \mathrm{Me} \cdot \mathrm{HBF}_{4}$ (15 mol \%), $\mathrm{Cs}_{2} \mathrm{CO}_{3}(3.0$ equiv), toluene $/ \mathrm{H}_{2} \mathrm{O}[0.42 \mathrm{M}], 120{ }^{\circ} \mathrm{C}, 48 \mathrm{~h}$.

8i) were also synthesized from the corresponding migratory Suzuki-Miyaura products (see Figure 2a).

Arguably, one of the most powerful features of migratory cross-couplings is their ability to transform regio- and stereoisomers into a single product. To demonstrate this, besides the convergence from $(Z)$ - and $(E)$-alkenes shown above (see Figure 2a), we engaged a 1:1 mixture of two positional isomers (1c, 1f), which indeed furnished a single coupling product (3c) in quantitative yield and perfect regioselectivity (Scheme $2 \mathrm{c}$ ).

To gain insights into the mechanism and the factors influencing the chain-walk process, we then performed some additional test reactions. The reaction was first carried out with para-trifluoromethylbromobenzene and para-bromoanisole to further investigate the influence of the electronic properties of the electrophile (Figure 3a). An electron-withdrawing substituent (3af) provided a slightly better selectivity compared to an electron-donating one (3ag). On the other

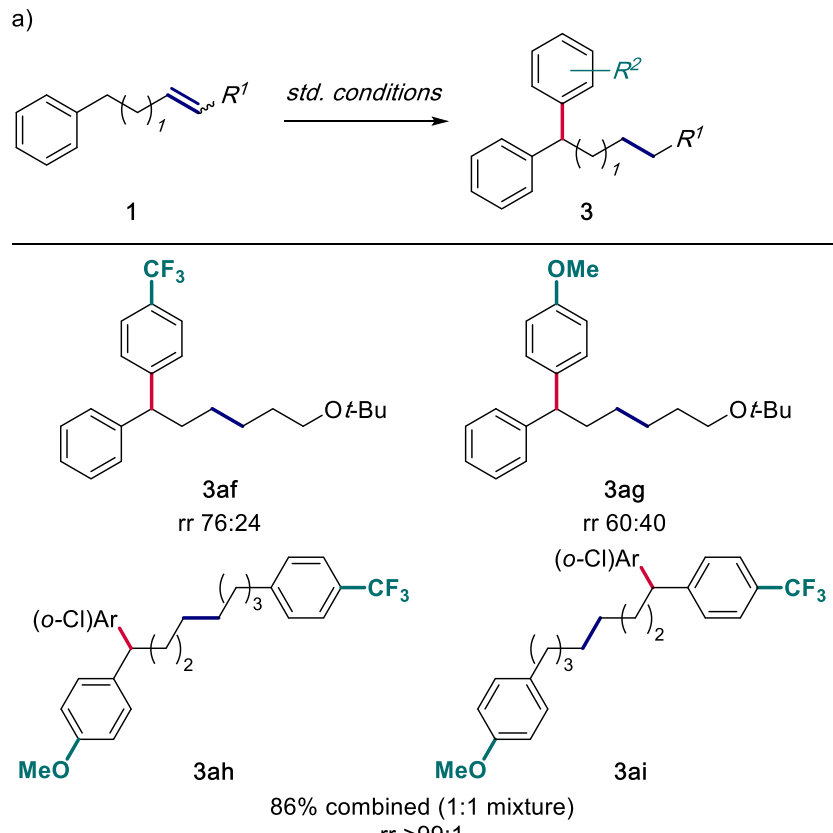
rr >99:1

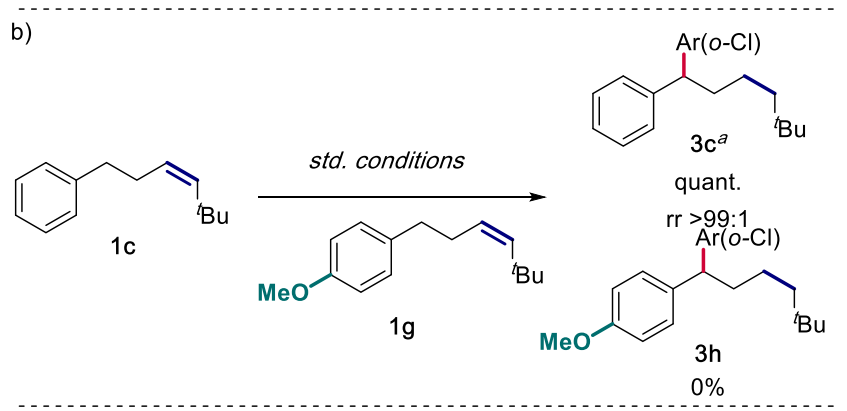

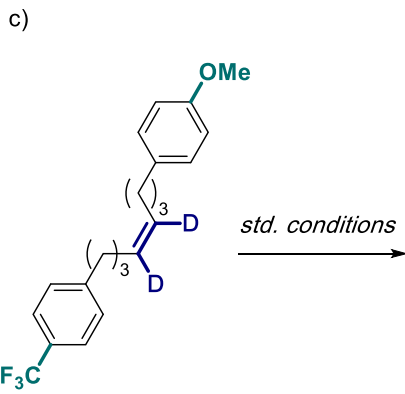

$1 \mathrm{~h}$ 3ah- $D_{2}$, 3ai- $D_{2}$

$86 \%$ combined (1:1 mixture) rr $>99: 1$

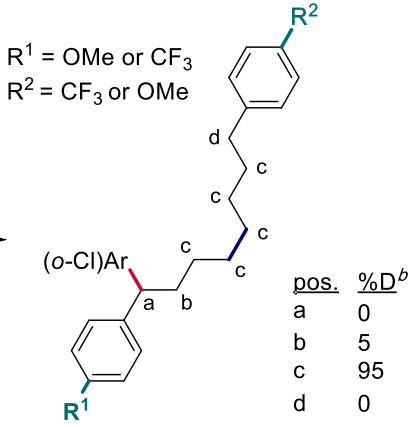

Figure 3. Mechanistic studies. Yields refer to the isolated product; rr of benzylic/sum of other regioisomers were determined by GCMS analysis of the crude reaction mixture. ${ }^{\text {a }}$ Standard reaction conditions: alkene (1.2 equiv), $\mathrm{BH}_{3} \cdot \mathrm{DMS}$ ( 1.4 equiv), toluene, $25 \rightarrow 60^{\circ} \mathrm{C}, 1 \mathrm{~h}$, then quench with $\mathrm{H}_{2} \mathrm{O}$ (11 equiv), $60{ }^{\circ} \mathrm{C}, 1 \mathrm{~h}$, then add $\mathrm{ArBr}(1.0$ equiv), $\mathrm{Pd}(\mathrm{TFA})_{2}(5 \mathrm{~mol} \%), \mathrm{P}\left({ }^{t} \mathrm{Bu}_{2}\right) \mathrm{Me} \cdot \mathrm{HBF}_{4}(15 \mathrm{~mol} \%), \mathrm{Cs}_{2} \mathrm{CO}_{3}$ (3.0 equiv), toluene $/ \mathrm{H}_{2} \mathrm{O}[0.42 \mathrm{M}], 120^{\circ} \mathrm{C}, 48 \mathrm{~h}$. ${ }^{\mathrm{b}}$ Yield determined by ${ }^{1} \mathrm{H}$ NMR using $\mathrm{CH}_{2} \mathrm{Br}_{2}$ as the internal standard. ${ }^{c}$ Deuterium contents determined by ${ }^{2} \mathrm{H}$ NMR analysis. (a) Influence of the substituents on both partners on the regioselectivity. (b) Crossover experiment. (c) Isotopic labeling experiment. 
hand, we already showed that electronically diverse orthosubstituents such as methyl (3y), methoxy (3z), or trifluoromethyl (3aa) provided excellent regioselectivities (see Figure $2 \mathrm{~b}$ ). These results combined indicate that steric factors on the aryl electrophile have a more pronounced influence than electronic effects, similar to the migratory Negishi coupling. ${ }^{1 \mathrm{c}}$ In contrast, a 1:1 ratio of products $3 \mathrm{ah}$ and 3ai was observed with an alkyl chain containing an electron-rich and an electron-poor arene on each end, hence showing that the aryl group on the alkylboronic acid partner has no influence on the selectivity. Next, a crossover experiment was carried out to further assess whether the palladium hydride intermediate dissociates during the chainwalk process (Figure $3 \mathrm{~b}$ ). This crossover experiment was performed by adding an alkene bearing a substituent on the aryl group $(\mathbf{1 g})$ to the reaction mixture after the hydroboration of $1 \mathrm{c}$. The lack of product containing the methoxy substituent (3h) is indicative of a nondissociative chain-walk process, ${ }^{4 \mathrm{~d}}$ similar to other migratory cross-couplings investigated by our group. $^{10-12}$

Furthermore, we performed an experiment from deuterated alkene $\mathbf{l h}$ to determine if deuterium scrambling occurs and to what positions (Figure 3c). Remarkably, no deuterium was observed in any of the two benzylic positions (a, d), indicating that the Pd migration to the benzylic position is irreversible. This observation is in agreement with the fact that the electronic properties of the benzylic position do not influence the selectivity (Figure 3a, bottom). Interestingly, only little incorporation of deuterium was measured in both homobenzylic positions $(\sim 5 \%)$, whereas all the remaining methylene groups bear deuterium atoms, which also indicates that $\beta$ hydride elimination to reach the benzylic position is favored over the back-migration. Altogether, these results indicate that the benzylpalladium intermediate acts as a thermodynamic sink within the migration pathway.

To summarize, the following catalytic cycle is proposed for the current migratory Suzuki-Miyaura coupling (Scheme 3). The oxidative addition of the electrophile to the in situgenerated $\mathrm{Pd}^{0}$ catalyst $\mathbf{I}$ gives intermediate II. Then, the hydroxypalladium species III, obtained after ligand exchange, undergoes transmetalation with the alkylboronic acid obtained by alkene hydroboration, yielding intermediate IV. ${ }^{18 \mathrm{~b}, 22}$ At this point, reductive elimination would furnish the direct coupling product, but using a small and electron-rich ligand and an ortho-substituted $\mathrm{Ar}^{1}$ group significantly increases its activation barrier as proposed by density functional theory calculations for related cross-couplings. ${ }^{10 a, b}$ Instead, the alkylpalladium species IV goes through a series of $\beta$-hydride elimination $/ \pi$ bond rotation/insertion steps, also referred to as chain-walking, until the palladium species reaches a benzylic position. The reductive elimination barrier is lower at the benzylic position, and therefore, reductive elimination of the palladium intermediate VII furnishes the benzylic cross-coupling product 3 at the expense of other regioisomers, while regenerating the $\mathrm{Pd}^{0}$ catalyst.

\section{CONCLUSIONS}

In conclusion, we have developed a highly selective and efficient palladium-catalyzed benzylic-selective migratory Suzuki-Miyaura cross-coupling for the synthesis of 1,1-diarylalkanes from cheap and readily available chemicals, that is, alkenes, borane, and bromoarenes. The designed one-pot procedure for the synthesis of B-alkyl boronic acids and their
Scheme 3. Proposed Catalytic Cycle ${ }^{a}$

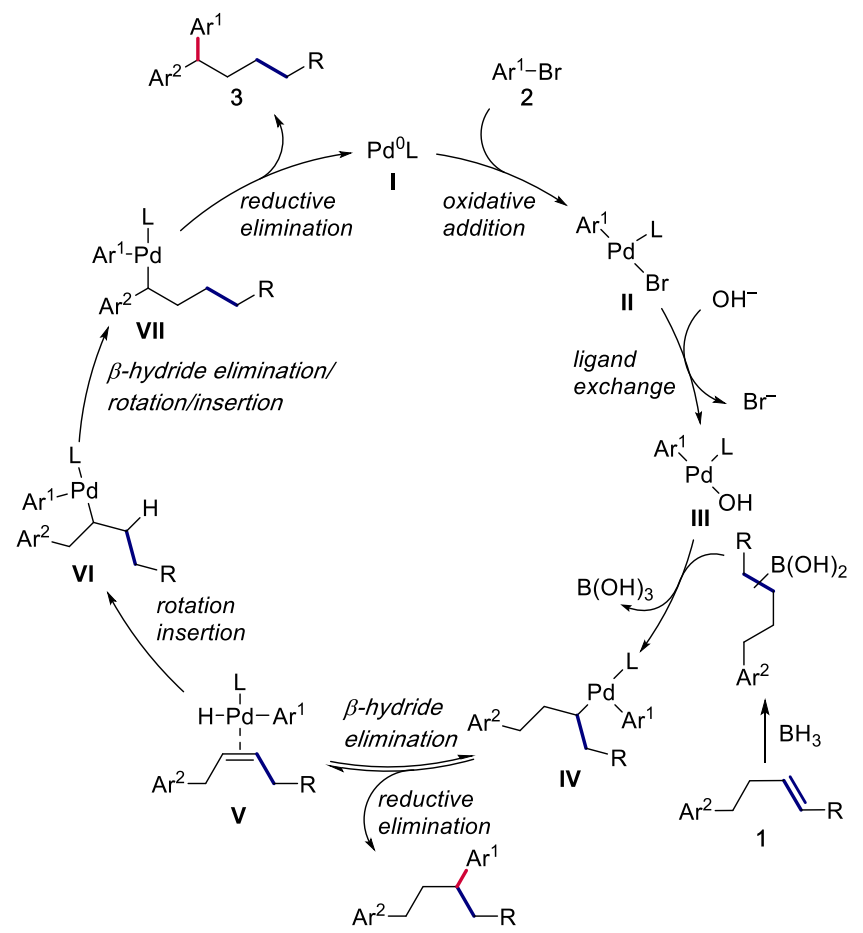

${ }^{a}$ Generation of the active $\mathrm{Pd}^{0}$ catalyst has been omitted for clarity.

subsequent cross-coupling avoided the difficult purification and isolation of these intermediates. Employing an ortho-chloro substituent on the electrophile as a removable directing group allowed for a broad diversity of substitution patterns and postfunctionalization reactions. The regioconvergent nature and the long-range migration of this transformation further demonstrated its practical value. Additionally, mechanistic experiments indicated a partially reversible nondissociative Pdmigration along the alkyl chain until the stabilized benzylic position, where reductive elimination is facile.

\section{ASSOCIATED CONTENT}

Full experimental and characterization data, including copies of ${ }^{1} \mathrm{H},{ }^{13} \mathrm{C}$, and ${ }^{19} \mathrm{~F}$ NMR spectra (PDF)

\section{AUTHOR INFORMATION}

\section{Corresponding Author}

Olivier Baudoin - Department of Chemistry, University of

Basel, CH-4056 Basel, Switzerland; 이이.org/0000-0002-

0847-8493; Email: olivier.baudoin@unibas.ch

\section{Author}

Yann Baumgartner - Department of Chemistry, University of Basel, CH-4056 Basel, Switzerland

\section{Notes}

The authors declare no competing financial interest. 


\section{ACKNOWLEDGMENTS}

This research was financially supported by the Swiss National Science Foundation (200021_165987) and the University of Basel. We thank Prof. Dr. Daniel Häussinger for assistance with NMR experiments and Dr. Michael Pfeffer for MS measurements. We also thank Daiki Kato, Diana Cavalli, Benjamin Manser, and Jonas Fürst who contributed to this project during internships.

\section{REFERENCES}

(1) Metal-Catalyzed Cross-Coupling Reactions and More; de Meijere, A., Bräse, S., Oestreich, M., Eds.; Wiley-VCH: Weinheim, Germany, 2014; Vol. 1-3.

(2) Hartwig, J. F. Evolution of C-H Bond Functionalization from Methane to Methodology. J. Am. Chem. Soc. 2016, 138, 2-24.

(3) For selected reviews: (a) Jazzar, R.; Hitce, J.; Renaudat, A.; Sofack-Kreutzer, J.; Baudoin, O. Functionalization of Organic Molecules by Transition-Metal-Catalyzed $\mathrm{C}\left(\mathrm{sp}^{3}\right)-\mathrm{H}$ Activation. Chem.-Eur. J. 2010, 16, 2654-2672. (b) Li, H.; Li, B.-J.; Shi, Z.-J. Challenge and Progress: Palladium-Catalyzed $\mathrm{sp}^{3} \mathrm{C}-\mathrm{H}$ Activation. Catal. Sci. Technol. 2011, 1, 191-206. (c) Hartwig, J. F.; Larsen, M. A. Undirected, Homogeneous C-H Bond Functionalization: Challenges and Opportunities. ACS Cent. Sci. 2016, 2, 281-292. (d) He, J.; Wasa, M.; Chan, K. S. L.; Shao, Q.; Yu, J.-Q. Palladium-Catalyzed Transformations of Alkyl C-H Bonds. Chem. Rev. 2017, 117, 87548786. (e) Chu, J. C. K.; Rovis, T. Complementary Strategies for Directed $\mathrm{C}\left(\mathrm{sp}^{3}\right)-\mathrm{H}$ Functionalization: A Comparison of TransitionMetal-Catalyzed Activation, Hydrogen Atom Transfer, and Carbene/ Nitrene Transfer. Angew. Chem., Int. Ed. 2018, 57, 62-101.

(4) For selected reviews: (a) Franzoni, I.; Mazet, C. Recent Trends in Pd-Catalyzed Remote Functionalization of Carbonyl Compounds. Org. Biomol. Chem. 2014, 12, 233-241. (b) Vasseur, A.; Bruffaerts, J.; Marek, I. Remote Functionalization through Alkene Isomerization. Nat. Chem. 2016, 8, 209-219. (c) Sommer, H.; Juliá-Hernández, F.; Martin, R.; Marek, I. Walking Metals for Remote Functionalization. ACS Cent. Sci. 2018, 4, 153-165. (d) Kochi, T.; Kanno, S.; Kakiuchi, F. Nondissociative Chain Walking as a Strategy in Catalytic Organic Synthesis. Tetrahedron Lett. 2019, 60, 150938. (e) Janssen-Müller, D.; Sahoo, B.; Sun, S.-Z.; Martin, R. Tackling Remote sp ${ }^{3} \mathrm{C}-\mathrm{H}$ Functionalization via Ni-Catalyzed "Chain-Walking" Reactions. Isr. J. Chem. 2020, 60, 195-206.

(5) For recent examples: (a) Masarwa, A.; Didier, D.; Zabrodski, T.; Schinkel, M.; Ackermann, L.; Marek, I. Merging Allylic CarbonHydrogen and Selective Carbon-Carbon Bond Activation. Nature 2014, 505, 199-203. (b) Mola, L.; Sidera, M.; Fletcher, S. P. Asymmetric Remote C-H Functionalization: Use of Internal Olefins in Tandem Hydrometallation-Isomerization-Asymmetric Conjugate Addition Sequences. Aust. J. Chem. 2015, 68, 401-403. (c) Gao, Y.; Yang, C.; Bai, S.; Liu, X.; Wu, Q.; Wang, J.; Jiang, C.; Qi, X. VisibleLight-Induced Nickel-Catalyzed Cross-Coupling with Alkylzirconocenes from Unactivated Alkenes. Chem 2020, 6, 675-688. (d) Matt, C.; Kern, C.; Streuff, J. Zirconium-Catalyzed Remote Defunctionalization of Alkenes. ACS Catal. 2020, 10, 6409-6413.

(6) For recent examples: (a) Obligacion, J. V.; Chirik, P. J. Bis(imino)pyridine Cobalt-Catalyzed Alkene Isomerization-Hydroboration: A Strategy for Remote Hydrofunctionalization with Terminal Selectivity. J. Am. Chem. Soc. 2013, 135, 19107-19110. (b) Yamakawa, T.; Yoshikai, N. Alkene Isomerization-Hydroarylation Tandem Catalysis: Indole C2-Alkylation with Aryl-Substituted Alkenes Leading to 1,1-Diarylalkanes. Chem.-Asian J. 2014, 9, 1242-1246. (c) Scheuermann, M. L.; Johnson, E. J.; Chirik, P. J. Alkene Isomerization-Hydroboration Promoted by PhosphineLigated Cobalt Catalysts. Org. Lett. 2015, 17, 2716-2719. (d) Chen, X.; Cheng, Z.; Guo, J.; Lu, Z. Asymmetric Remote C-H Borylation of Internal Alkenes via Alkene Isomerization. Nat. Commun. 2018, 9, 3939.

(7) For recent examples: (a) Lee, W.-C.; Wang, C.-H.; Lin, Y.-H.; Shih, W.-C.; Ong, T.-G. Tandem Isomerization and C-H Activation:
Regioselective Hydroheteroarylation of Allylarenes. Org. Lett. 2013, 15, 5358-5361. (b) Bair, J. S.; Schramm, Y.; Sergeev, A. G.; Clot, E.; Eisenstein, O.; Hartwig, J. F. Linear-Selective Hydroarylation of Unactivated Terminal and Internal Olefins with TrifluoromethylSubstituted Arenes. J. Am. Chem. Soc. 2014, 136, 13098-13101. (c) Buslov, I.; Becouse, J.; Mazza, S.; Montandon-Clerc, M.; Hu, X. Chemoselective Alkene Hydrosilylation Catalyzed by Nickel Pincer Complexes. Angew. Chem., Int. Ed. 2015, 54, 14523-14526. (d) He, Y.; Cai, Y.; Zhu, S. Mild and Regioselective Benzylic C-H Functionalization: Ni-Catalyzed Reductive Arylation of Remote and Proximal Olefins. J. Am. Chem. Soc. 2017, 139, 1061-1064. (e) JuliáHernández, F.; Moragas, T.; Cornella, J.; Martin, R. Remote Carboxylation of Halogenated Aliphatic Hydrocarbons with Carbon Dioxide. Nature 2017, 545, 84-88. (f) Peng, L.; Li, Y.; Li, Y.; Wang, W.; Pang, H.; Yin, G. Ligand-Controlled Nickel-Catalyzed Reductive Relay Cross-Coupling of Alkyl Bromides and Aryl Bromides. ACS Catal. 2018, 8, 310-313. (g) Wang, Z.; Yin, H.; Fu, G. C. Catalytic Enantioconvergent Coupling of Secondary and Tertiary Electrophiles with Olefins. Nature 2018, 563, 379-383. (h) Basnet, P.; Dhungana, R. K.; Thapa, S.; Shrestha, B.; KC, S.; Sears, J. M.; Giri, R. NiCatalyzed Regioselective $\beta, \delta$-Diarylation of Unactivated Olefins in Ketimines via Ligand-Enabled Contraction of Transient Nickellacycles: Rapid Access to Remotely Diarylated Ketones. J. Am. Chem. Soc. 2018, 140, 7782-7786. (i) Zhou, L.; Zhu, C.; Bi, P.; Feng, C. NiCatalyzed Migratory Fluoro-alkenylation of Unactivated Alkyl Bromides with gem-Difluoroalkenes. Chem. Sci. 2019, 10, 11441149. (j) Jiao, K. J.; Liu, D.; Ma, H. X.; Qiu, H.; Fang, P.; Mei, T. S. Nickel-Catalyzed Electrochemical Reductive Relay Cross-Coupling of Alkyl Halides to Aryl Halides. Angew. Chem., Int. Ed. 2020, 59, 65206524. (k) Kumar, G. S.; Peshkov, A.; Brzozowska, A.; Nikolaienko, P.; Zhu, C.; Rueping, M. Nickel-Catalyzed Chain-Walking CrossElectrophile Coupling of Alkyl and Aryl Halides and Olefin Hydroarylation Enabled by Electrochemical Reduction. Angew. Chem., Int. Ed. 2020, 59, 6513-6519. (1) Li, Y.; Luo, Y.; Peng, L.; Li, Y.; Zhao, B.; Wang, W.; Pang, H.; Bai, R.; Lan, Y.; Yin, G. Reaction Scope and Mechanistic Insights of Nickel-Catalyzed Migratory Suzuki-Miyaura Cross-Coupling. Nat. Commun. 2020, 11, 417. (m) He, Y.; Liu, C.; Yu, L.; Zhu, S. Ligand-Enabled Nickel-Catalyzed Redox-Relay Migratory Hydroarylation of Alkenes with Arylborons. Angew. Chem., Int. Ed. 2020, 59, 9186-9191.

(8) For recent examples: (a) Grotjahn, D. B.; Larsen, C. R.; Gustafson, J. L.; Nair, R.; Sharma, A. Extensive Isomerization of Alkenes Using a Bifunctional Catalyst: An Alkene Zipper. J. Am. Chem. Soc. 2007, 129, 9592-9593. (b) Dobereiner, G. E.; Erdogan, G.; Larsen, C. R.; Grotjahn, D. B.; Schrock, R. R. A One-Pot Tandem Olefin Isomerization/Metathesis-Coupling (ISOMET) Reaction. ACS Catal. 2014, 4, 3069-3076. (c) Ho, G. M.; Judkele, L.; Bruffaerts, J.; Marek, I. Metal-Catalyzed Remote Functionalization of $\omega$-Ene Unsaturated Ethers: Towards Functionalized Vinyl Species. Angew. Chem., Int. Ed. 2018, 57, 8012-8016.

(9) For recent examples: (a) Werner, E. W.; Mei, T.-S.; Burckle, A. J.; Sigman, M. S. Enantioselective Heck Arylations of Acyclic Alkenyl Alcohols Using a Redox-Relay Strategy. Science 2012, 338, 14551458. (b) Stokes, B. J.; Opra, S. M.; Sigman, M. S. PalladiumCatalyzed Allylic Cross-Coupling Reactions of Primary and Secondary Homoallylic Electrophiles. J. Am. Chem. Soc. 2012, 134, 1140811411. (c) Kochi, T.; Hamasaki, T.; Aoyama, Y.; Kawasaki, J.; Kakiuchi, F. Chain-Walking Strategy for Organic Synthesis: Catalytic Cycloisomerization of 1,n-Dienes. J. Am. Chem. Soc. 2012, 134, 16544-16547. (d) Mei, T.-S.; Werner, E. W.; Burckle, A. J.; Sigman, M. S. Enantioselective Redox-Relay Oxidative Heck Arylations of Acyclic Alkenyl Alcohols using Boronic Acids. J. Am. Chem. Soc. 2013, 135, 6830-6833. (e) Mei, T.-S.; Patel, H. H.; Sigman, M. S. Enantioselective Construction of Remote Quaternary Stereocentres. Nature 2014, 508, 340-344. (f) Larionov, E.; Lin, L.; Guénée, L.; Mazet, C. Scope and Mechanism in Palladium-Catalyzed Isomerizations of Highly Substituted Allylic, Homoallylic, and Alkenyl Alcohols. J. Am. Chem. Soc. 2014, 136, 16882-16894. (g) Patel, H. H.; Sigman, M. S. Palladium-Catalyzed Enantioselective Heck 
Alkenylation of Acyclic Alkenols Using a Redox-Relay Strategy. J. Am. Chem. Soc. 2015, 137, 3462-3465. (h) Zhang, C.; Santiago, C. B.; Kou, L.; Sigman, M. S. Alkenyl Carbonyl Derivatives in Enantioselective Redox Relay Heck Reactions: Accessing $\alpha, \beta$ Unsaturated Systems. J. Am. Chem. Soc. 2015, 137, 7290-7293. (i) Lin, L.; Romano, C.; Mazet, C. Palladium-Catalyzed Long-Range Deconjugative Isomerization of Highly Substituted $\alpha, \beta$-Unsaturated Carbonyl Compounds. J. Am. Chem. Soc. 2016, 138, 10344-10350. (j) Singh, S.; Bruffaerts, J.; Vasseur, A.; Marek, I. A Unique PdCatalysed Heck Arylation as a Remote Trigger for Cyclopropane Selective Ring-Opening. Nat. Commun. 2017, 8, 14200. (k) Kohler, D. G.; Gockel, S. N.; Kennemur, J. L.; Waller, P. J.; Hull, K. L. PalladiumCatalysed anti-Markovnikov Selective Oxidative Amination. Nat. Chem. 2018, 10, 333-340. (1) Bruffaerts, J.; Pierrot, D.; Marek, I. Efficient and Stereodivergent Synthesis of Unsaturated Acyclic Fragments Bearing Contiguous Stereogenic Elements. Nat. Chem. 2018, 10, 1164-1170. (m) Zhang, X.-M.; Yang, J.; Zhuang, Q.-B.; Tu, Y.-Q.; Chen, Z.; Shao, H.; Wang, S.-H.; Zhang, F.-M. Allylic Arylation of 1,3-Dienes via Hydroboration/Migrative Suzuki-Miyaura CrossCoupling Reactions. ACS Catal. 2018, 8, 6094-6099.

(10) (a) Renaudat, A.; Jean-Gérard, L.; Jazzar, R.; Kefalidis, C. E.; Clot, E.; Baudoin, O. Palladium-Catalyzed $\beta$ Arylation of Carboxylic Esters. Angew. Chem., Int. Ed. 2010, 49, 7261-7265. (b) Larini, P.; Kefalidis, C. E.; Jazzar, R.; Renaudat, A.; Clot, E.; Baudoin, O. On the Mechanism of the Palladium-Catalyzed $\beta$-Arylation of Ester Enolates. Chem.-Eur. J. 2012, 18, 1932-1944. (c) Aspin, S.; Goutierre, A.-S.; Larini, P.; Jazzar, R.; Baudoin, O. Synthesis of Aromatic $\alpha$ Aminoesters: Palladium-Catalyzed Long-Range Arylation of Primary $\mathrm{C}_{\mathrm{sp} 3}-\mathrm{H}$ Bonds. Angew. Chem., Int. Ed. 2012, 51, 10808-10811. (d) Aspin, S.; López-Suárez, L.; Larini, P.; Goutierre, A.-S.; Jazzar, R.; Baudoin, O. Palladium-Catalyzed $\beta$-Arylation of Silyl Ketene Acetals and Application to the Synthesis of Benzo-Fused $\delta$-Lactones. Org. Lett. 2013, 15, 5056-5059.

(11) (a) Millet, A.; Larini, P.; Clot, E.; Baudoin, O. LigandControlled $\beta$-Selective $\mathrm{C}\left(\mathrm{sp}^{3}\right)-\mathrm{H}$ Arylation of $\mathrm{N}$-Boc-Piperidines. Chem. Sci. 2013, 4, 2241-2247. (b) Millet, A.; Dailler, D.; Larini, P.; Baudoin, O. Ligand-Controlled $\alpha$ - and $\beta$-Arylation of Acyclic N-Boc Amines. Angew. Chem., Int. Ed. 2014, 53, 2678-2682. (c) Dupuy, S.; Zhang, K.-F.; Goutierre, A.-S.; Baudoin, O. Terminal-Selective Functionalization of Alkyl Chains by Regioconvergent CrossCoupling. Angew. Chem., Int. Ed. 2016, 55, 14793-14797. (d) Lin, W.; Zhang, K.-F.; Baudoin, O. Regiodivergent Enantioselective C-H Functionalization of Boc-1,3-oxazinanes for the Synthesis of $\beta^{2}$ - and $\beta^{3}$-Amino Acids. Nat. Catal. 2019, 2, 882-888.

(12) Baudoin, O. Selectivity Control in the Palladium-Catalyzed Cross-coupling of Alkyl Nucleophiles. Chimia 2016, 70, 768-772.

(13) For examples of direct Pd-catalyzed Suzuki-Miyaura crosscoupling of benzylic organoboranes, see: (a) Imao, D.; Glasspoole, B. W.; Laberge, V. S.; Crudden, C. M. Cross Coupling Reactions of Chiral Secondary Organoboronic Esters with Retention of Configuration. J. Am. Chem. Soc. 2009, 131, 5024-5025. (b) Ohmura, T.; Awano, T.; Suginome, M. Stereospecific Suzuki-Miyaura Coupling of Chiral $\alpha$-(Acylamino)benzylboronic Esters with Inversion of Configuration. J. Am. Chem. Soc. 2010, 132, 13191-13193. (c) Awano, T.; Ohmura, T.; Suginome, M. Inversion or Retention? Effects of Acidic Additives on the Stereochemical Course in Enantiospecific SuzukiMiyaura Coupling of $\alpha$-(Acetylamino)benzylboronic Esters. J. Am. Chem. Soc. 2011, 133, 20738-20741. (d) Matthew, S. C.; Glasspoole, B. W.; Eisenberger, P.; Crudden, C. M. Synthesis of Enantiomerically Enriched Triarylmethanes by Enantiospecific Suzuki-Miyaura CrossCoupling Reactions. J. Am. Chem. Soc. 2014, 136, 5828-5831. (e) Lou, Y.; Cao, P.; Jia, T.; Zhang, Y.; Wang, M.; Liao, J. CopperCatalyzed Enantioselective 1,6-Boration ofpara-Quinone Methides and Efficient Transformation ofgem-Diarylmethine Boronates to Triarylmethanes. Angew. Chem., Int. Ed. 2015, 54, 12134-12138.

(14) (a) Dreher, S. D.; Dormer, P. G.; Sandrock, D. L.; Molander, G. A. Efficient Cross-Coupling of Secondary Alkyltrifluoroborates with Aryl Chlorides-Reaction Discovery Using Parallel Microscale Experimentation. J. Am. Chem. Soc. 2008, 130, 9257-9259. (b) Li, H.;
Zhong, Y.-L.; Chen, C.-Y.; Ferraro, A. E.; Wang, D. A Concise and Atom-Economical Suzuki-Miyaura Coupling Reaction Using Unactivated Trialkyl- and Triarylboranes with Aryl Halides. Org. Lett. 2015, 17, 3616-3619.

(15) For examples: (a) Wanner, C.; Wieland, H.; Schollmeyer, P.; Hörl, W. H. Beclobrate: Pharmacodynamic Properties and Therapeutic Use in Hyperlipidemia. Eur. J. Clin. Pharmacol. 1991, 40, S85-S89. (b) Silva, D. H. S.; Davino, S. C.; Barros, S. B. d. M.; Yoshida, M. Dihydrochalcones and Flavonolignans from Iryanthera lancifolia. Nat. Prod. 1999, 62, 1475-1478. (c) McRae, A. L.; Brady, K. T. Review of Sertraline and its Clinical Applications in Psychiatric Disorders. Expert Opin. Pharmacother. 2001, 2, 883-892. (d) Malhotra, B.; Gandelman, K.; Sachse, R.; Wood, N.; Michel, M. The Design and Development of Fesoterodine as a Prodrug of 5- Hydroxymethyl Tolterodine (5-HMT), the Active Metabolite of Tolterodine. Curr. Med. Chem. 2009, 16, 4481-4489. (e) Messaoudi, S.; Hamze, A.; Provot, O.; Tréguier, B.; Rodrigo De Losada, J.; Bignon, J.; Liu, J.-M.; Wdzieczak-Bakala, J.; Thoret, S.; Dubois, J.; Brion, J.-D.; Alami, M. Discovery of Isoerianin Analogues as Promising Anticancer Agents. ChemMedChem 2011, 6, 488-497.

(16) Cone angles $\left({ }^{\circ}\right): \mathrm{PCy}_{3}, 170 ; \mathrm{P}\left({ }^{t} \mathrm{Bu}\right)_{2} \mathrm{Me}, 161 ; \mathrm{P}^{i} \mathrm{Pr}_{3}, 160$. Lee, K. J.; Brown, T. L. Molecular Mechanics Model of Ligand Effects. 2. Binding of Phosphines to $\mathrm{Cr}(\mathrm{CO})_{5}$. Inorg. Chem. 1992, 31, 289-294.

(17) Zhao, S.; Gensch, T.; Murray, B.; Niemeyer, Z. L.; Sigman, M. S.; Biscoe, M. R. Enantiodivergent Pd-catalyzed C-C bond formation enabled through ligand parameterization. Science 2018, 362, 670-674.

(18) (a) Chemler, S. R.; Trauner, D.; Danishefsky, S. J. The B-Alkyl Suzuki-Miyaura Cross-Coupling Reaction: Development, Mechanistic Study, and Applications in Natural Product Synthesis. Angew. Chem., Int. Ed. 2001, 40, 4544-4568. (b) Lennox, A. J. J.; Lloyd-Jones, G. C. Selection of boron reagents for Suzuki-Miyaura coupling. Chem. Soc. Rev. 2014, 43, 412-443.

(19) (a) Sun, H.-X.; Sun, Z.-H.; Wang, B. B-Alkyl Suzuki-Miyaura cross-coupling of tri-n-alkylboranes with arylbromides bearing acidic functions under mild non-aqueous conditions. Tetrahedron Lett. 2009, 50, 1596-1599. (b) Wang, B.; Sun, H.-X.; Sun, Z.-H.; Lin, G.-Q. Direct B-Alkyl Suzuki-Miyaura Cross-Coupling of Trialkyl- boranes with Aryl Bromides in the Presence of Unmasked Acidic or Basic Functions and Base-Labile Protections under Mild Non-Aqueous Conditions. Adv. Synth. Catal. 2009, 351, 415-422. (c) Monot, J.; Brahmi, M. M.; Ueng, S.-H.; Robert, C.; Murr, M. D.-E.; Curran, D. P.; Malacria, M.; Fensterbank, L.; Lacote, E. Suzuki-Miyaura Coupling of NHC-Boranes: A New Addition to the C-C Coupling Toolbox. Org. Lett. 2009, 11, 4914-4917.

(20) Navarro, O.; Kaur, H.; Mahjoor, P.; Nolan, S. P. CrossCoupling and Dehalogenation Reactions Catalyzed by (N-Heterocyclic carbene) $\mathrm{Pd}(\mathrm{allyl}) \mathrm{Cl}$ Complexes. J. Org. Chem. 2004, 69, 31733180.

(21) Song, J.; Li, Y.; Sun, W.; Yi, C.; Wu, H.; Wang, H.; Ding, K.; Xiao, K.; Liu, C. Efficient Palladium-Catalyzed $\mathrm{C}\left(\mathrm{sp}^{2}\right)-\mathrm{H}$ Activation towards the Synthesis of Fluorenes. New J. Chem. 2016, 40, 90309033.

(22) (a) Carrow, B. P.; Hartwig, J. F. Distinguishing Between Pathways for Transmetalation in Suzuki-Miyaura Reactions. J. Am. Chem. Soc. 2011, 133, 2116-2119. (b) Amatore, C.; Le Duc, G.; Jutand, A. Mechanism of Palladium-Catalyzed Suzuki-Miyaura Reactions: Multiple and Antagonistic Roles of Anionic "Bases" and Their Countercations. Chem.-Eur. J. 2013, 19, 10082-10093. 